\title{
Mixed primary prostatic carcinoma with acinar, neuroendocrine and ductal components
}

\author{
Alfredo E. Romero-Rojas ${ }^{1}$, Julio A. Diaz-Perez ${ }^{1,2,3}$, Abhinay Reddy ${ }^{2}$ \\ ${ }^{1}$ National Institute of Cancer, Bogotá, Colombia; \\ ${ }^{2}$ University of California San Diego, La Jolla, CA, USA; \\ ${ }^{3}$ University of Santander, Bucaramanga, Colombia.
}

\begin{abstract}
Summary Mixed tumors in the prostate gland have been described; they are primarily originate in the gland or are the product of metastatic compromise. Mixed primary epithelial carcinomas of the prostate are very rare; here we report the case of a 72-years-old man with histopathologic findings of a primary prostate mixed carcinoma, showing characteristics of acinar, ductal and neuroendocrine adenocarcinoma. We also discuss the clinical, diagnostic, and therapeutic aspects of these uncommon mixed neoplasms.
\end{abstract}

KEY WORDS: Prostatic carcinoma; Neuroendocrine carcinoma; Ductal carcinoma; Acinar adenocarcinoma; Mixed tumor.

Submitted 15 March 2014; Accepted 31 May 2014

\section{Case Report}

Here we report the case of a 72-year-old man with histopathologic findings of primary prostate mixed carcinoma, showing characteristics of acinar, ductal and neuroendocrine adenocarcinoma. We also discuss the clini$\mathrm{cal}$, diagnostic, and therapeutic aspects of these uncommon mixed tumors.

Case report and Figures are posted in Suppementary materials on www.aiua.it

\section{Discussion}

Mixed prostatic carcinomas are rare; they demonstrate a combination of malignant epithelial or sarcomatoid components $(1,4)$. The epithelial variant of these carcinomas is often a high-grade acine adenocarcinoma mixed with squamous, urothelial, neuroendocrine, ductal, mucinous (colloid), signet ring, oncocytic, basal cell, and lymphoepithelioma-like components (4). The origin and utility of identification of these mixed carcinomas has been highly controversial; they have been thought by some authors to be derived from a single cell of origin, and are the product of one or multiple types of differentiation or metaplastic changes, rather than representing a combination of separate epithelial neoplasms. However the hypothesis of neoplasm collision has been formulated, in which these neoplasms develop independently in the prostate $(14,15)$ formed by heterologous elements with lack of morphological and immunophenotipical connection. In our case we found a similar immunophenotypical pattern that is in accordance with the first hypothesis that is also supported by previous studies with analysis of loss-of-heterozygosity (14-16). Also multiple authors and classifications refer to these mixed tumors as descriptive variants with no known prognostic significance other than that of acinar adenocarcinoma $(2,7,9)$, but it is currently known that these tumors are aggressive neoplasms with an associated poor prognosis (7), and an actual risk of death of $20 \%$ within one year of diagnosis.

Clinically, most patients are older (range 50-89) and present with urinary tract obstruction and symptoms of frequency, urgency, and nocturia (4), similar to our case. Other secondary symptoms including bilateral flank pain, microscopic hematuria, and renal insufficiency are also reported (7). Serum PAP and PSA can be normal or elevated $(4,7,12)$. In about half of the cases, the initial biopsy diagnosis is an acinar (conventional) adenocarcinoma, followed by hormonal and/or radiation therapy, with a subsequent diagnosis of the mixed component in the histopathologic analysis of the surgical specimen (13).

The histopathological analysis conducted with hematoxilin and eosin and is the key to allow for a correct diagnosis and evade diagnostic pitfalls in these tumors. Microscopically, the morphology is highly variable and is challenging for the pathologist; metastatic tumors from other sites need to be considered in the differential diagnosis $(16,17)$. The most common primary sites of tumors to be considered and excluded in the differential diagnosis include carcinomas from the bladder and colon (17). Clinical exams by cystoscopy, colonoscopy, chest and abdominal tomography, and others are helpful $(16,17)$, also a careful immunophenotypical examination, with PSA, prostein (P501S), AMACR, PAP and CK7 positivity, and b-catenin, and CDX2 negativity are beneficial $(13,15,18,19)$. Other markers such as thrombo- 
modulin, uroplakin and villin that have been used in identifying tumors of urothelial and colonic origin have suboptimal sensitivities (15). Immunohistochemistry is also relevant in proving different types of elements, which may be unapparent on hematoxylin and eosin (H\&E)-stained sections, like neuroendocrine areas (13). The present case is unique, since a combination of primary acinar, neuroendocrine and ductal adenocarcinoma has not been previously reported in the literature, although is mentioned as a possibility in the Rosai textbook (20). In our case the proliferation index assessed by the Ki 67 antigen was high in all the components, in accordance with some previous reports (21), and in disagreement with other reports (8), suggesting that the labeling index is variable, and also suggesting that in combined mixed tumors, the choice of the treatment should dictated by the tumor type and stage $(1,14)$.

Due to the limited experience, there are no standard treatment recommendations for the management of mixed tumors of the prostate. Operable carcinomas are frequently treated with surgery (8). Surgeries with curative intent include radical retro-pubic prostatectomy, radical cysto-prostatectomy, supra-pubic prostatectomy, and pelvic exenteration $(8,10)$. Non-surgical therapy (androgen ablation treatment and chemotherapy) seems to be ineffective, and androgen deprivation therapy might provide palliative relief; however, $55.5 \%$ of patients are unresponsive to conventional chemotherapy (8).

In conclusion, we presented a case of mixed epithelial prostatic malignant tumor, and we discussed clinically relevant aspects for the correct diagnosis and management of these neoplasms, and posit that a careful immuno-phenotypical evaluation is needed to generate a correct diagnosis.

\section{REFERENCES}

1. Adlakha H, Bostwick DG. Paneth cell-like change in prostatic adenocarcinoma represents neuroendocrine differentiation: report of 30 cases. Hum Pathol. 1994; 25:135-9.

2. Mazzucchelli R, Lopez-Beltran A, Cheng L, et al. Rare and unusual histological variants of prostatic carcinoma: clinical significance. BJU Int. 2008; 102:1369-74.

3. Ergen A, Balbay MD, Irwin M, Torno R. Collision metastasis of bladder and prostate carcinoma to a single pelvic lymph node. Int Urol Nephrol. 1995; 27:743-5.

4. Parwani AV, Kronz JD, Genega EM, et al. Prostate carcinoma with squamous differentiation: an analysis of 33 cases. Am J Surg Pathol. 2004; 28:651-7.

5. Hansel DE, Epstein JI. Sarcomatoid carcinoma of the prostate: a study of 42 cases. Am J Surg Pathol. 2006; 30:1316-21.
6. Oliai BR, Kahane H, Epstein JI. A clinicopathologic analysis of urothelial carcinomas diagnosed on prostate needle biopsy. Am J Surg Pathol. 2001; 25:794-801.

7. Rogers CG, Parwani A, Tekes A, et al. Carcinosarcoma of the prostate with urothelial and squamous components. J Urol. 2005; $173: 439-40$

8. Parada D, Peña KB, Riu F. Sarcomatoid carcinoma of the prostate: ductal adenocarcinoma and stromal sarcoma-like appearance: a rare association. Case Rep Urol. 2011; $2011: 702494$.

9. Epstein JI, Algaba F, Yang XJ, et al. Tumours of the prostate. In Eble JN, Sauter G, Epstein JI, Sesterhenn IA eds, Tumours of the Urinary System and Male Genital Organs, Chapter 3. Lyon: IARC Press, 2004:160-208.

10. Curtis MW, Evans AJ, Srigley JR. Mucin-producing urothelialtype adenocarcinoma of prostate: report of two cases of a rare and diagnostically challenging entity. Mod Pathol. 2005; 18:585-90.

11. Osunkoya AO, Epstein JI. Primary mucin-producing urothelialtype adenocarcinoma of prostate: report of 15 cases. Am J Surg Pathol. 2007; 31:1323-9.

12. Rahmanou F, Koo J, Marinbakh AY, et al. Squamous cell carcinoma at the prostatectomy site: squamous differentiation of recurrent prostate carcinoma. Urology. 1999; 54:744.

13. Tamas EF, Epstein JI. Prognostic significance of paneth cell-like neuroendocrine differentiation in adenocarcinoma of the prostate. Am J Surg Pathol. 2006; 30:980-5.

14. Egilmez T, Bal N, Guvel S, et al. Adenosquamous carcinoma of the prostate. Int J Urol. 2005; 12:319-21.

15. Chuang AY, DeMarzo AM, Veltri RW, et al. Immunohistochemical differentiation of high-grade prostate carcinoma from urothelial carcinoma. Am J Surg Pathol. 2007; 31:1246-55.

16. Gohji K, Nomi M, Kizaki T, et al. "Collision phenomenon" of prostate and bladder cancers in lymph node metastases. Int J Urol. 1997; 4:222-4.

17. Ergen A, Balbay MD, Irwin M, Torno R. Collision metastasis of bladder and prostate carcinoma to a single pelvic lymph node. Int Urol Nephrol. 1995; 27:743-5.

18. Wang W, Epstein JI. Small cell carcinoma of the prostate. A morphologic and immunohistochemical study of 95 cases. Am J Surg Pathol. 2008; 32:65-71.

19. Cohen RJ, Wheeler TM, Bonkhoff H, Rubin MA. A proposal on the identification, histologic reporting, and implications of intraductal prostatic carcinoma. Arch Pathol Lab Med. 2007; 131:1103-9.

20. Rosai J. Male reproductive system - prostate and seminal vesicles, chapter 18. In: Rosai J. Rosai and Ackerman's Surgical Pathology. Mosby; 10 edition 2011.

21. Pacchioni D, Casetta G, Piovano M, et al. Prostatic duct carcinoma with combined prostatic duct adenocarcinoma and urothelial carcinoma features: report of a case. Int J Surg Pathol. 2004; 12:293-7.

\section{Correspondence}

Alfredo E. Romero-Rojas, MD (Corresponding Author)

National Institute of Cancer, Bogotá, Colombia

Julio A. Diaz-Perez, MD, MS

jdiazperez@ucsd.edu

Stein Clinical Research Building 245, University of California

San Diego, 9500 Gilman Drive, La Jolla, CA 92093-0637

Abhinay Reddy, BS, MS

University of Santander, Bucaramanga, Colombia 